\title{
Drug therapy for multiple sclerosis
}

\author{
Eleonora Tavazzi MD, Marco Rovaris MD, Loredana La Mantia MD
}

$\mathrm{U}$ ntil two decades ago, steroids were the only available treatment for multiple sclerosis (MS). Recently, several new compounds have been developed and approved with the aim of favourably changing the disease course, but with varied success. The evaluation of the effectiveness of treatments for MS is complex, and identifying the most appropriate treatment for an individual patient may be difficult. The main criteria used to verify treatment efficacy in MS studies are based on clinical measures of disease activity, such as the relapse rate and the cumulative progression of disability over time. Clinical data are always related to magnetic resonance imaging (MRI) parameters, such as the number and volume of new lesions and of contrastenhancing lesions - thought to reflect inflammatory disease activity - as well as measures of brain atrophy that suggest neural degeneration.

We review high-quality evidence of the efficacy of disease-modifying agents (interferons and glatiramer acetate), selective immunosuppressive agents (natalizumab and fingolimod) and recently approved drugs (teriflunomide and dimethyl fumarate) for the relapsing-remitting form of MS and indirectly compare their pharmacologic and clinical effects and safety profiles (Box 1). We also review the latest pharmacologic research in this field, which continues to be active and addresses three main needs: a more selective drug target among the immune-mediated pathogenetic components of MS, a more effective action on neural degeneration and the ability to promote reparative mechanisms.

\section{What is MS?}

Multiple sclerosis is a chronic demyelinating disease of the central nervous system, driven by two main pathogenetic mechanisms: inflammation and degeneration. The former is principally related to the occurrence of acute episodes of neurologic dysfunction (relapses) and the formation of focal demyelinating lesions in the brain and the spine. The latter is mainly responsible for progression of disability. The disease occurs in different clinical forms, possibly related to the varying interplay of these pathogenetic mechanisms (Box 2).

\section{What are the available treatments and their biological mechanisms?}

\section{Steroids}

Steroids have been used for the treatment of MS for a long time. They inhibit lymphocyte activation and reduce production of proinflammatory cytokines and migration of immune cells into the central nervous system. ${ }^{2}$ This reduces brain MRI activity (the number of contrast-enhancing lesions). ${ }^{3}$ The use of steroids for MS is limited by their well-known contraindications and adverse effects (e.g., diabetes, hypertension and osteoporosis).

\section{Glatiramer acetate}

Glatiramer acetate is a synthetic amino acid polymer resembling myelin basic protein. It acts by promoting a shift from a proinflammatory to an antiinflammatory immune system setting, ${ }^{4}$ thereby reducing the number of active MRI lesions and the relapse rate 5 (Table 1). Moreover, MRI studies have shown that glatiramer acetate affects measures of tissue degeneration, such as the loss of brain vol$u^{13}{ }^{13}$ and the formation of black holes, which suggests that the drug may promote remyelination. ${ }^{4}$

Glatiramer acetate is a safe, well-tolerated drug with minor adverse effects, such as postinjection skin reactions and (rarely) a self-limited, systemic postinjection reaction characterized by flushing, chest pain, fast heartbeat, anxiety and shortness of breath (Table 1). Glatiramer acetate seems to be safe during pregnancy. ${ }^{14}$
Competing interests: None declared.

This article has been peer reviewed.

Correspondence to:

Loredana La Mantia, lamantialore@gmail.com

CMAJ 2014. DOI:10.1503 /cmaj.130727

\section{- Ker poInts}

- Currently available medications for the treatment of relapsingremitting MS are heterogeneous in terms of efficacy (higher for natalizumab and fingolimod) and safety profile (better for glatiramer acetate and interferon- $\beta$ ).

- Disease-modifying treatments should be started early in patients with relapsing-remitting MS.

- Multiple sclerosis relapses should be treated with short courses of steroids to favour faster clinical recovery.

- The choice of medication in patients naive to treatment should be made on an individual basis, with consideration for both medical indications and patient expectations.

- A shift to natalizumab or fingolimod treatment is recommended if there is a poor response to glatiramer acetate or interferon- $\beta$. 


\section{Interferon $\beta-1 a$ and $\mathbf{- 1 b}$}

Interferon- $\beta$ promotes the production of antiinflammatory cytokines and decreases the production of proinflammatory ones by reducing the trafficking of inflammatory cells within the central nervous system. The inhibition of inflammation induced by interferon- $\beta$ treatment leads to reductions in the formation of new MRI lesions and the relapse rate ${ }^{6-8}$ (Table 1). Experimental data show that this compound may also promote the production of nerve growth factor, ${ }^{15}$ which suggests reparative mechanisms.

The most common adverse effects of interferon- $\beta$ are postinjection flu-like syndrome, skin reactions, mild leukopenia, and reversible thyroid and liver dysfunction (Table 1).

\section{Natalizumab}

Natalizumab, the first monoclonal antibody approved for the treatment of MS, interacts with $\alpha 4$ integrin receptors on the surface of lymphocytes, preventing these cells from adhering to the blood-brain barrier and entering the central nervous system. ${ }^{16}$ Natalizumab decreases the number of contrast-enhancing and new MRI lesions,

\section{Box 1: Evidence used in this review}

We searched Ovid MEDLINE and the Cochrane Library for articles published from 1982 to April 2013. The search term "multiple sclerosis" was combined with "steroids," "interferon beta," "glatiramer acetate," "natalizumab," "fingolimod," "fumarate," "teriflunomide," "immunosuppressant," "mitoxantrone," "cyclophosphamide," "azathioprine," "MRI" (magnetic resonance imaging) and "response to treatment." We restricted our review to articles published in English. We considered the data from systematic reviews and randomized controlled trials as high-level evidence and therefore discussed them in this review. We also decided to include a few open-label studies describing the efficacy of drug treatments for long-term clinical and MRI outcomes. The only original articles reported in this paper not belonging to the previously mentioned categories concern studies describing the biological mechanisms of action of the therapies. Other findings related to the efficacy of drugs for clinical and MRI outcomes were classified as low-level evidence.

\section{Box 2: Clinical forms of MS}

Multiple sclerosis can be classified according to four main clinical phenotypes:

- Relapsing-remitting MS (85\% of patients), characterized by relapses followed by total or partial recovery. The first clinical manifestation of relapsing-remitting MS is called clinically isolated syndrome.

- Primary progressive MS ( $10 \%$ of patients), characterized by a slow progression of disability, with little or no evidence of inflammatory activity.

- Secondary progressive MS (30\%-40\% of patients) follows a course of relapsing-remitting MS after 10-15 years from disease onset. ${ }^{1}$ It is characterized by progression of neurologic disability with or without superimposed relapses.

- Progressive-relapsing MS (5\% of patients), characterized from onset by a progressive course with superimposed relapses followed by complete or partial recovery. the relapse rate and the cumulative probability of progression' ${ }^{9}$ (Table 1). It also reduces the proportion of new MRI lesions that become persistent black holes, which suggests an inhibition of the mechanisms leading to axonal damage. ${ }^{17}$

The main complication of natalizumab treatment is the risk of progressive multifocal leukoencephalopathy, a severe, potentially lifethreatening central nervous system infection caused by the reactivation of JC virus. JC virus is widespread in the population and usually remains quiescent in the kidneys, but it can reactivate and cause encephalitis in patients with immunosuppression. The clinical onset of progressive multifocal leukoencephalopathy may resemble a relapse of MS and therefore requires a careful diagnostic workup and appropriate treatment. ${ }^{18}$ Clinicians should consider the risk factors for progressive multifocal leukoencephalopathy as a combination of three conditions: treatment with natalizumab lasting longer than two years, prior use of immunosuppressants and the presence of anti-JC virus antibodies. In patients without antiJC virus antibodies, the estimated risk of progressive multifocal leukoencephalopathy is less than 0.1 per 1000 patients, whereas in patients with all three conditions, the risk is 11.1 per $1000 .^{19}$

\section{Fingolimod}

Fingolimod is the first oral treatment available for MS. It acts by internalizing the sphingosine-1 receptors, which are expressed on lymphocyte surfaces, thus preventing T-cell migration from secondary lymphoid organs to circulating blood. ${ }^{20}$ In a placebo-controlled trial, patients given fingolimod had reduced MRI activity and relapse rate (Table 1$).{ }^{10}$ In addition, a reduced loss of brain volume in patients given the drug compared with placebo was reported in a pivotal trial. ${ }^{21}$ These findings indicate that fingolimod may have both anti-inflammatory and neuroprotective effects.

Because sphingosine-1 receptors are also present in cardiac tissue, their block may lead to bradycardia and delayed atrioventricular conduction delay. Therefore, cardiovascular monitoring is needed for six hours after the first administration of fingolimod. Moreover, the use of the drug is associated with leukopenia, increased risk of infections (mainly related to varicella-zoster virus), macular edema, increased risk of skin cancer and liver dysfunction.

\section{Traditional immunosuppressants}

Mitoxantrone interferes with RNA synthesis and inhibits DNA repair. ${ }^{22}$ In a randomized multicentre study, mitoxantrone treatment combined with steroids reduced the proportion of patients with new contrast-enhancing MRI lesions after 6 
Table 1: Summary of clinical findings from randomized controlled trials of drugs used for disease-modifying treatment of relapsing-remitting multiple sclerosis

\begin{tabular}{|c|c|c|c|c|c|}
\hline Drug & $\begin{array}{l}\text { Treatment } \\
\text { regimen }\end{array}$ & $\begin{array}{c}\text { Trial } \\
\text { duration, yr }\end{array}$ & $\begin{array}{l}\text { Annualized } \\
\text { relapse rate (\% } \\
\text { reduction v. } \\
\text { placebo) }\end{array}$ & $\begin{array}{l}\text { Progression to disability* } \\
\text { (\% reduction v. placebo) }\end{array}$ & Adverse effects \\
\hline $\begin{array}{l}\text { Glatiramer } \\
\text { acetate }^{5}\end{array}$ & $\begin{array}{l}20 \mathrm{mg} \mathrm{SC} \\
\text { daily }\end{array}$ & 2 & $\begin{array}{l}\text { Drug: } 0.59 \\
\text { Placebo: } 0.84 \\
(29 \%)\end{array}$ & $\begin{array}{l}\% \text { of patients without } \\
\text { progression: } \\
\text { Drug: } 78.4 \\
\text { Placebo: } 75.4 \\
(12 \% ; \text { NSt) }\end{array}$ & $\begin{array}{l}\text { - Local reaction at injection } \\
\text { site } \\
\text { - Systemic reaction after } \\
\text { injection } \\
\text { - Allergic reaction }\end{array}$ \\
\hline Interferon $\beta-1 b^{6}$ & $\begin{array}{l}250 \mu \mathrm{g} S \mathrm{SC} \\
\text { every other } \\
\text { day }\end{array}$ & 3 & $\begin{array}{l}\text { Drug: } 0.84 \\
\text { Placebo: } 1.17 \\
(28 \%)\end{array}$ & $\begin{array}{l}\% \text { of patients with stable } \\
\text { EDSS score: } \\
\text { Drug: } 73 \\
\text { Placebo: } 61 \\
(29 \% ; p=0.161)\end{array}$ & $\begin{array}{l}\text { - Local reaction at injection } \\
\text { site } \\
\text { - Flu-like syndrome after } \\
\text { injection } \\
\text { - Liver and thyroid dysfunction } \\
\text { (usually reversible) } \\
\text { - Leukopenia } \\
\text { - Mood disorders }\end{array}$ \\
\hline Interferon $\beta-1 a^{7}$ & $\begin{array}{l}30 \mu \mathrm{g} \mathrm{IM} \\
\text { weekly }\end{array}$ & 2 & $\begin{array}{l}\text { Drug: } 0.61 \\
\text { Placebo: } 0.9 \\
(32 \%)\end{array}$ & $\begin{array}{l}\text { \% of patients with } \\
\text { disability progression: } \\
\text { Drug: } 21.9 \\
\text { Placebo: } 34.9 \\
(37 \%)\end{array}$ & Same as interferon $\beta-1 b$ \\
\hline Interferon $\beta-1 a^{8}$ & $\begin{array}{l}22 \text { or } 44 \mu \mathrm{g} \\
\text { SC, } 3 \text { times } \\
\text { weekly }\end{array}$ & 2 & $\begin{array}{l}\text { Drug } 22 \mu \mathrm{g}: 1.82 \\
\text { Drug } 44 \mu \mathrm{g}: 1.73 \\
\text { Placebo: } 2.56 \\
(22 \mu \mathrm{g}: 27 \% ; \\
44 \mu \mathrm{g}: 33 \%)\end{array}$ & $\begin{array}{l}\text { 1st quartile time to } \\
\text { progression in months: } \\
\text { Drug } 22 \mu \mathrm{g}: 18.5 \\
\text { Drug } 44 \mu \mathrm{g}: 21.3 \\
\text { Placebo: } 11.9 \\
(22 \mu \mathrm{g}: \mathrm{NA} ; 44 \mu \mathrm{g}: 30 \%)\end{array}$ & Same as interferon $\beta$-1b \\
\hline Natalizumab ${ }^{9}$ & $\begin{array}{l}300 \text { mg IV } \\
\text { monthly }\end{array}$ & 2 & $\begin{array}{l}\text { Drug: } 0.24 \\
\text { Placebo: } 075 \\
(68 \%)\end{array}$ & $\begin{array}{l}\text { Cumulative probability of } \\
\text { progression: } \\
\text { Drug: } 17 \\
\text { Placebo: } 29 \\
(42 \%)\end{array}$ & $\begin{array}{l}\text { - Liver dysfunction } \\
\text { - Allergic reactions } \\
\text { - Progressive multifocal } \\
\text { leukoencephalopathy }\end{array}$ \\
\hline Fingolimod $^{10}$ & $\begin{array}{l}0.5 \mathrm{mg} P O \\
\text { daily }\end{array}$ & 2 & $\begin{array}{l}\text { Drug: } 0.18 \\
\text { Placebo: } 0.24 \\
(54 \%)\end{array}$ & $\begin{array}{l}\text { Cumulative probability of } \\
\text { progression: } \\
\text { Drug: } 17.7 \\
\text { Placebo: } 24.1 \\
(32 \%)\end{array}$ & $\begin{array}{l}\text { - Liver dysfunction } \\
\text { - Bradycardia, increased QT } \\
\text { interval } \\
\text { - Leukopenia and } \\
\text { lymphopenia } \\
\text { - Increased risk of varicella- } \\
\text { zoster virus infection } \\
\text { - Macular edema }\end{array}$ \\
\hline $\begin{array}{l}\text { Dimethyl } \\
\text { fumarate }^{11}\end{array}$ & $\begin{array}{l}240 \mathrm{mg} P O \\
\text { twice daily }\end{array}$ & 2 & $\begin{array}{l}\text { Drug: } 0.36 \\
\text { Placebo: } 0.17 \\
(53 \%)\end{array}$ & $\begin{array}{l}\text { \% of patients with } \\
\text { disability progression: } \\
\text { Drug: } 16 \\
\text { Placebo: } 27 \\
(38 \%)\end{array}$ & $\begin{array}{l}\text { - Flushing } \\
\text { - Gastrointestinal disturbances } \\
\text { (nausea, diarrhea) } \\
\text { - Lymphopenia }\end{array}$ \\
\hline Teriflunomide $^{12}$ & $\begin{array}{l}14 \mathrm{mg} P O \\
\text { daily }\end{array}$ & 2 & $\begin{array}{l}\text { Drug: } 0.37 \\
\text { Placebo: } 0.54 \\
(31 \%)\end{array}$ & $\begin{array}{l}\text { \% of patients with } \\
\text { disability progression: } \\
\text { Drug: } 20.2 \\
\text { Placebo: } 27.3 \\
(29.8 \%)\end{array}$ & $\begin{array}{l}\text { - Gastrointestinal disturbances } \\
\text { (nausea, diarrhea) } \\
\text { - Urinary tract infection } \\
\text { - Liver dysfunction } \\
\text { - Leukopenia } \\
\text { - Teratogenic effects }\end{array}$ \\
\hline
\end{tabular}


months compared with steroids alone $(90 \% \mathrm{v}$. $30 \%) .{ }^{23}$ Adverse effects are nausea and vomiting, alopecia, urinary tract infections and infertility. Mitoxantrone has been approved for the treatment of worsening MS, with a warning about the risk of cardiotoxicity (which is dependent on the cumulative dose) and leukemia, occurring in $12 \%$ and $0.8 \%$ of patients, respectively. ${ }^{24,25}$

Cyclophosphamide and azathioprine have been considered as potential therapies for MS with immunosuppressive effects. Cyclophosphamide is an alkylating agent of DNA, and azathioprine is a purine antagonist that affects DNA replication. Their actions seem to reduce inflammatory activity in the central nervous system, as confirmed by MRI studies. However, their safety profiles are characterized by several adverse effects, such as leukopenia with increased risk of infection, nausea and alopecia for cyclophosphamide therapy ${ }^{26}$ and a possible long-term risk of malignant growth related to the duration of treatment and cumulative dose for azathioprine therapy. ${ }^{27}$

\section{New treatments under investigation}

\section{Dimethyl fumarate and teriflunomide}

Dimethyl fumarate acts by inhibiting proinflammatory cytokines and activating an antioxidant pathway in response to the cytotoxic effects of oxidative stress. In a phase III trial, dimethyl fumarate treatment reduced MRI activity and the relapse rate ${ }^{11}$ (Table 1). Reported adverse effects include gastrointestinal problems, flushing, lymphopenia and liver dysfunction.

Teriflunomide reversibly inhibits a mitochondrial enzyme required for pyrimidine synthesis, blocking the activation and proliferation of stimulated lymphocytes. In a placebo-controlled randomized trial, its anti-inflammatory activity was confirmed by a reduced relapse rate and the lower numbers of contrast-enhancing lesions in the treatment group. ${ }^{12}$ Adverse effects are diarrhea, nausea, elevated liver enzyme levels and hair thinning. The main concern with teriflunomide use is a teratogenic effect shown in different animal species. Therefore, women of child-bearing age must be using a reliable contraception method before use. Before pregnancy is attempted, a washout period of at least six months must be observed, or a procedure of accelerated drug elimination must be started with cholestyramine or activated charcoal powder.

\section{Alemtuzumab}

Alemtuzumab, already approved for the treatment of B-cell chronic lymphocytic leukemia, is a monoclonal antibody directed against the CD52 antigen, leading to a profound depletion of circulating lymphocytes. Phase $\mathrm{II}^{28}$ and phase III trials $^{29,30}$ showed a consistent efficacy of this compound in reducing anti-inflammatory activity, shown by both clinical and MRI outcomes in both MS patients naive to treatments and those who had not responded to glatiramer acetate or interferon- $\beta$. The risk-benefit profile of alemtuzumab is affected by several safety concerns, related to the frequent (up to 19\%) induction of autoimmune diseases such as idiopathic thrombocytopenic purpura and Graves disease. Alemtuzumab has been approved by the European Medical Agency for the treatment of relapsingremitting MS in adults with active disease defined by clinical or imaging features. However, the US Food and Drug Administration recently raised strong concerns about its safety and efficacy, and quality of the trials. ${ }^{31}$

\section{How should the different stages and clinical forms of MS be treated?}

Pharmacologic treatment in MS has two main goals: to facilitate recovery from relapse and to reduce the risk of relapses and progression of disability. Treatment of disease-related symptoms (e.g., spasticity, pain, sphincter disturbances and fatigue) is also important, but it is beyond the scope of this review.

\section{Treating relapses}

Steroids are considered the elective therapy for MS relapses. A meta-analysis of randomized controlled trials (RCTs) found that disabilityrelated symptoms were less likely to worsen or remained the same within the first five weeks if steroid treatment was started within two to eight weeks after relapse, compared with the placebo (odds ratio $0.37,95 \%$ confidence interval 0.24 0.57). ${ }^{32}$ The most common treatment regimen is the intravenous use of methylprednisolone $(1 \mathrm{~g} / \mathrm{d}$ for three to five consecutive days). Notably, a systematic review showed that oral and intravenous administrations of steroids have similar efficacies. ${ }^{33}$ This information could have a substantial impact on clinical practice by allowing outpatient instead of hospital management of relapses in many instances.

\section{Disease modification}

Treating relapsing-remitting MS and clinically isolated syndrome

Potential options for drug treatment throughout the course of relapsing-remitting MS are depicted in Figure 1. Some studies indicate that the chronic 
administration of steroids in the form of repeated pulse therapy with high-dose methylprednisolone given intravenously might favourably modify the course of MS, reducing the risk of relapse and the accumulation of disability. ${ }^{34,35}$ Pulse methylprednisolone therapy also seems to be able to reduce the loss of brain volume on serial MRI scans. ${ }^{34}$ However, there is no evidence-based recommenda- tion for the use of this treatment regimen in clinical practice, and the adverse effects related to the chronic use of steroids also should be considered.

Several RCTs have shown that glatiramer acetate and interferon- $\beta$ reduce the risk of relapse and the accumulation of MRI lesion loads in relapsing-remitting $\mathrm{MS}^{6-8,36}$ starting from the earliest stage of clinical isolation of the syndrome..$^{37-40}$

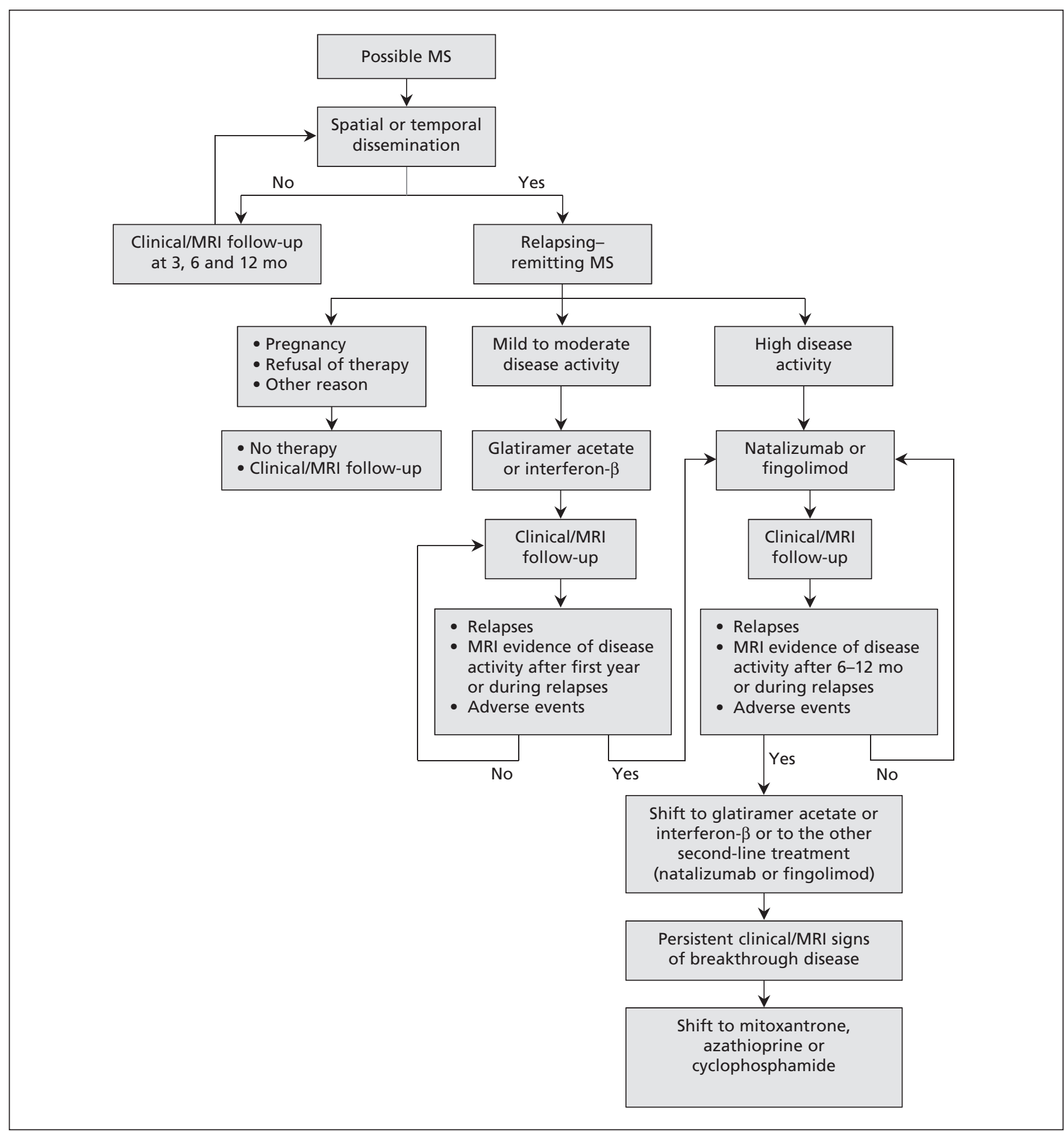

Figure 1: Potential drug treatment options throughout the course of relapsing-remitting multiple sclerosis (MS). Primary and secondary progressive MS are not shown because there is no treatment available for primary progressive MS, and interferon B-1b is the only drug approved for the treatment of secondary progressive MS. MRI = magnetic resonance imaging. 
For this reason, they are approved worldwide as first-line treatments for relapsing-remitting MS, whereas dimethyl fumarate and teriflunomide are prescribed only in a few countries at present (one being the United States, where the registration process was completed recently).

The efficacy of glatiramer acetate $(20 \mathrm{mg})$ has been shown in several RCTs $\mathrm{s}^{5,36,41}$ and confirmed in a systematic review, ${ }^{42}$ which reported that glatiramer acetate increased the probability of remaining relapse free after one year of treatment by $28 \%$ when compared with placebo. In a cohort of patients given glatiramer acetate for 15 years, a persistent reduction in relapse rate and a lower rate of conversion to secondary progressive MS were found ${ }^{43}$ However, the evidence on the drug's long-term efficacy is limited by the open-label design of the available studies, in which only patients given the drug were analyzed and dropouts were lost at follow-up.

Three different interferon- $\beta$ regimens are currently available and approved for the treatment of relapsing-remitting MS. Two involve different formulations of interferon $\beta-1 \mathrm{a}$ (30 $\mu \mathrm{g}$ intramuscularly once weekly; or 22 or $44 \mu$ g subcutaneously three times weekly), and the other uses interferon $\beta-1 \mathrm{~b}(250 \mu \mathrm{g}$ subcutaneously every other day). ${ }^{6-8,44}$ The treatment regimens showed similar efficacy in reducing the relapse rate and MRI activity in RCTs of disease-modifying drugs for the treatment of relapsing-remitting MS and clinically isolated syndrome (Table 1). The long-term efficacy of interferon- $\beta$ was studied in postmarketing settings, with conflicting results..$^{45,46}$

Published head-to-head trials did not show significant differences in clinical efficacy between glatiramer acetate and interferon- $\beta$, although interferon- $\beta$ may have an earlier and greater impact on MRI activity. ${ }^{47,48}$ Currently, there is insufficient evidence to recommend one drug over the other for patients with relapsing-remitting MS who are naive to treatment. There is evidence that the efficacy of interferon- $\beta$ and glatiramer acetate is maximized by an early initiation in patients with established relapsing-remitting $\mathrm{MS}^{49}$ and in patients with clinically isolated syndrome. . $^{37,50,51}$ However, a proper evaluation of the cost-benefit profile of these treatments remains difficult, and in some countries, the access to treatment for patients with clinically isolated syndrome is limited to those considered at high risk of a poor prognosis. ${ }^{52}$

Treatment with glatiramer acetate or interferon- $\beta$ does not need to be stopped after a given period, since it does not reach a toxic cumulative dosage, and long-term follow-up data confirm that it continues to be safe and may be effective after 15 years. ${ }^{43,45}$ Treatment with either of these drugs only needs to be stopped if it is not effective or not tolerated. The lack of response to interferon- $\beta$ may be due to the presence of circulating neutralizing antibodies. ${ }^{53}$ Their presence can be detected by means of measuring myxovirus resistance protein $\mathrm{A}$, a marker of the biological activity of interferon- $\beta$ whose expression is substantially reduced when these antibodies develop..$^{54}$ An evidence-based definition of the failure of interferon- $\beta$ treatment was published recently; ${ }^{55}$ however, the data needed for a definition of the failure of treatment with glatiramer acetate are not available.

Natalizumab and fingolimod, which can be considered selective immunosuppressant drugs, showed a greater efficacy on average for both clinical and MRI outcomes in RCTs than interferon- $\beta$ and glatiramer acetate did in the treatment of relapsing-remitting MS (Table 1). However, because of their risk-benefit profiles, natalizumab and fingolimod are reserved for use in patients with either breakthrough disease or a poor response to interferon- $\beta$ or glatiramer acetate. In the US, fingolimod can be prescribed to patients with relapsing-remitting MS independent of the aforementioned criteria. The withdrawal of natalizumab exposes patients to the risk of immune reconstitution inflammatory syndrome, characterized by intense inflammatory activity that results in severe multiple relapses and the formation of new lesions. On the other hand, patients taking natalizumab may develop neutralizing antibodies against the compound (associated with treatment failure $)^{56}$ and are at increased risk of time-related progressive multifocal leukoencephalopathy. At present, clear-cut evidence-based guidelines are not available, and the decision to stop treatment with natalizumab after the first two years has to be made after careful consideration of the risk-benefit profile for the individual patient.

Considering both their severe adverse effects and the limited evidence supporting their efficacy, mitoxantrone, azathioprine and cyclophosphamide should be used only in patients with relapsing-remitting MS when all other options are contraindicated or not effective.

In the event of treatment failure, different strategies can be adopted. Considering that glatiramer acetate and interferon- $\beta$ have different mechanisms of action, shifting from one drug to the other can be considered to avoid the risks related to the use of natalizumab and fingolimod, although this strategy is not supported by proper evidence. The shift to second-line therapy with natalizumab has been shown to be effective, ${ }^{57}$ however, evidence is lacking on the effectiveness of fingolimod as a second-line therapy. Any shift 
from natalizumab to fingolimod to avoid the risk of progressive multifocal leukoencephalopathy, as well as shifts from traditional immunosuppressants to other treatment regimens, must have an adequate washout period (three to six months) to avoid complications related to the altered immune setting.

\section{Treating secondary progressive MS}

Interferon $\beta-1 b$ is the only approved treatment for secondary progressive MS. The approval was based on a single $\mathrm{RCT}^{58}$ in which the drug reduced the accumulation of disability over two years. A recent systemic review showed that the observed effect might be due to a reduction of superimposed relapses rather than to a true prevention of disease progression..$^{59}$ An ongoing RCT is assessing the efficacy of natalizumab in patients with secondary progressive MS.

\section{Treating primary progressive MS}

There is no evidence-based, disease-modifying treatment for this phenotype of MS. However, two RCTs of glatiramer acetate ${ }^{60}$ and rituximab ${ }^{61}$ for the treatment of primary progressive MS showed that these drugs had some efficacy in reducing the progression of disability in subgroups of patients (e.g., males, patients with short disease duration and those with persistent MRI activity). Ongoing RCTs are testing the efficacy of natalizumab and fingolimod as treatments for primary progressive MS.

\section{Gaps in knowledge}

Several important areas of the pharmacologic management of MS need further investigation. The long-term efficacy of drug treatments is unknown in terms of the accumulation of disability and the prognosis of relapsing-remitting MS. A better understanding of the neuroprotective effects of available drugs and newer compounds is needed. Evidence of effective treatments for secondary and primary progressive MS is lacking. Finally, evidence-based guidelines concerning which drugs to choose and when and how to change the therapeutic regimen during the course of the disease are needed to help physicians in the management of individual MS patients.

\section{References}

1. Rovaris M, Confavreux C, Furlan R, et al. Secondary progressive multiple sclerosis: current knowledge and future challenges. Lancet Neurol 2006;5:343-54.

2. Sloka JS, Stefanelli M. The mechanism of action of methylprednisolone in the treatment of multiple sclerosis. Mult Scler 2005; 11:425-32.

3. Martinelli V, Rocca MA, Annovazzi P, et al. A short-term randomized MRI study of high-dose oral vs intravenous methylprednisolone in MS. Neurology 2009;73:1842-8.
4. Aharoni R. The mechanism of action of glatiramer acetate and beyond. Autoimmun Rev 2013;12:543-53.

5. Comi G, Filippi M, Wolinsky JS. European/Canadian multicenter, double-blind, randomized, placebo-controlled study of the effects of glatiramer acetate on magnetic resonance imagingmeasured disease activity and burden in patients with relapsing multiple sclerosis. European/Canadian Glatiramer Acetate Study Group. Ann Neurol 2001;49:290-7.

6. Interferon beta-1b is effective in relapsing-remitting multiple sclerosis. I. Clinical results of a multicenter, randomized, double-blind, placebo-controlled trial. IFNB Multiple Sclerosis Study Group. Neurology 1993;43:655-61.

7. Jacobs LD, Cookfair DL, Rudick RA, et al. Intramuscular interferon beta-1a for disease progression in relapsing multiple sclerosis. The Multiple Sclerosis Collaborative Research Group (MSCRG). Ann Neurol 1996;39:285-94.

8. Randomised double-blind placebo-controlled study of interferon beta-1a in relapsing/remitting multiple sclerosis. PRISMS (Prevention of Relapses and Disability by Interferon beta-1a Subcutaneously in Multiple Sclerosis) Study Group. Lancet 1998;352: 1498-504.

9. Polman $\mathrm{CH}$, O'Connor PW, Havrdova E, et al. A randomized, placebo-controlled trial of natalizumab for relapsing multiple sclerosis. N Engl J Med 2006;354:899-910.

10. Kappos L, Radue EW, O'Connor P, et al. A placebo-controlled trial of oral fingolimod in relapsing multiple sclerosis. $N$ Engl J Med 2010;362:387-401.

11. Gold R, Kappos L, Arnold DL, et al. Placebo-controlled phase 3 study of oral BG-12 for relapsing multiple sclerosis. $N$ Engl $J$ Med 2012;367:1098-107.

12. O'Connor P, Wolinsky JS, Confavreux C, et al. Randomized trial of oral teriflunomide for relapsing multiple sclerosis. N Engl J Med 2011;365:1293-303.

13. Zivadinov R, Reder AT, Filippi M, et al. Mechanisms of action of disease-modifying agents and brain volume changes in multiple sclerosis. Neurology 2008;71:136-44.

14. Giannini M, Portaccio E, Ghezzi A, et al. Pregnancy and fetal outcomes after glatiramer acetate exposure in patients with multiple sclerosis: a prospective observational multicentric study. BMC Neurol 2012;12:124.

15. Biernacki K, Antel JP, Blain M, et al. Interferon beta promotes nerve growth factor secretion early in the course of multiple sclerosis. Arch Neurol 2005;62:563-8.

16. Mellergard J, Edstrom M, Vrethem M, et al. Natalizumab treatment in multiple sclerosis: marked decline of chemokines and cytokines in cerebrospinal fluid. Mult Scler 2010;16:208-17.

17. Dalton CM, Miszkiel KA, Barker GJ, et al. Effect of natalizumab on conversion of gadolinium enhancing lesions to T1 hypointense lesions in relapsing multiple sclerosis. J Neurol 2004;251:407-13.

18. Clifford DB, De Luca A, Simpson DM, et al. Natalizumabassociated progressive multifocal leukoencephalopathy in patients with multiple sclerosis: lessons from 28 cases. [published erratum in Lancet Neurol 2010;9:463]. Lancet Neurol 2010;9:438-46

19. Bloomgren G, Richman S, Hotermans C, et al. Risk of natalizumab-associated progressive multifocal leukoencephalopathy. N Engl J Med 2012;366:1870-80.

20. Cohen JA, Chun J. Mechanisms of fingolimod's efficacy and adverse effects in multiple sclerosis. Ann Neurol 2011;69:759-77.

21. Radue EW, O'Connor P, Polman CH, et al. Impact of fingolimod therapy on magnetic resonance imaging outcomes in patients with multiple sclerosis. Arch Neurol 2012;69:1259-69.

22. Fidler JM, DeJoy SQ, Gibbons JJ Jr. Selective immunomodulation by the antineoplastic agent mitoxantrone. I. Suppression of B lymphocyte function. J Immunol 1986;137:727-32.

23. Edan G, Miller D, Clanet M, et al. Therapeutic effect of mitoxantrone combined with methylprednisolone in multiple sclerosis: a randomised multicentre study of active disease using MRI and clinical criteria. J Neurol Neurosurg Psychiatry 1997;62:112-8.

24. Martinelli Boneschi F, Rovaris M, Capra R, et al. Mitoxantrone for multiple sclerosis. Cochrane Database Syst Rev 2005; (4):CD002127.

25. Marriott JJ, Miyasaki JM, Gronseth G, et al.; Therapeutics and Technology Assessment Subcommittee of the American Academy of Neurology. Evidence report: the efficacy and safety of mitoxantrone (Novantrone) in the treatment of multiple sclerosis: report of the Therapeutics and Technology Assessment Subcommittee of the American Academy of Neurology. Neurology 2010;74:1463-70.

26. La Mantia L, Milanese C, Mascoli N, et al. Cyclophosphamide for multiple sclerosis. Cochrane Database Syst Rev 2007; (1):CD002819.

27. Casetta I, Iuliano G, Filippini G. Azathioprine for multiple sclerosis. Cochrane Database Syst Rev 2007;(4):CD003982. 
28. Coles AJ, Compston DA, Selmaj KW, et al. Alemtuzumab vs. interferon beta-1a in early multiple sclerosis. $N$ Engl $\mathrm{J} \mathrm{Med}$ 2008;359:1786-801.

29. Coles AJ, Twyman CL, Arnold DL, et al. Alemtuzumab for patients with relapsing multiple sclerosis after diseasemodifying therapy: a randomised controlled phase 3 trial. Lancet 2012;380:1829-39.

30. Cohen JA, Coles AJ, Arnold DL, et al. Alemtuzumab versus interferon beta 1a as first-line treatment for patients with relapsing-remitting multiple sclerosis: a randomised controlled phase 3 trial. Lancet 2012;380:1819-28.

31. US Food and Drug Administration. Peripheral and Centra Nervous System Drugs Advisory Committee meeting - Alemtuzumab Advisory Committee background package (BLA 103948\5139). Available: www.fda.gov/downloads/advisory committees/committeemeetingmaterials/drugs/peripheraland centralnervoussystemdrugadvisorycommittee/ucm374188.pdf (accessed 2013 Nov.).

32. Filippini G, Brusaferri F, Sibley WA, et al. Corticosteroids or ACTH for acute exacerbations in multiple sclerosis. Cochrane Database Syst Rev 2000;(4):CD001331.

33. Burton JM, O'Connor PW, Hohol M, et al. Oral versus intravenous steroids for treatment of relapses in multiple sclerosis. Cochrane Database Syst Rev 2012;(3):CD006921.

34. Zivadinov R, Rudick RA, De Masi R, et al. Effects of IV methylprednisolone on brain atrophy in relapsing-remitting MS Neurology 2001;57:1239-47.

35. Ciccone A, Beretta S, Brusaferri F, et al. Corticosteroids for the long-term treatment in multiple sclerosis. Cochrane Database Syst Rev 2008;(1):CD006264

36. Johnson KP, Brooks BR, Cohen JA, et al. Copolymer 1 reduces relapse rate and improves disability in relapsing-remitting multiple sclerosis: results of a phase III multicenter, double-blind placebo-controlled trial. The Copolymer 1 Multiple Sclerosis Study Group. Neurology 1995;45:1268-76.

37. Kappos L, Polman CH, Freedman MS, et al. Treatment with interferon beta-1b delays conversion to clinically definite and McDonald MS in patients with clinically isolated syndromes. Neurology 2006;67:1242-9.

38. Comi G, Filippi M, Barkhof F, et al. Effect of early interferon treatment on conversion to definite multiple sclerosis: a randomised study. Lancet 2001;357:1576-82.

39. Jacobs LD, Beck RW, Simon JH, et al. Intramuscular interferon beta-1a therapy initiated during a first demyelinating event in multiple sclerosis. CHAMPS Study Group. N Engl J Med 2000; 343:898-904.

40. Kinkel RP, Kollman C, O'Connor P, et al. IM interferon beta-1a delays definite multiple sclerosis 5 years after a first demyelinating event. Neurology 2006;66:678-84

41. Bornstein MB, Miller A, Slagle S, et al. A pilot trial of Cop 1 in exacerbating-remitting multiple sclerosis. N Engl J Med 1987; 317:408-14.

42. La Mantia L, Munari LM, Lovati R. Glatiramer acetate for multiple sclerosis. Cochrane Database Syst Rev 2010;(5) CD004678.

43. Ford C, Goodman AD, Johnson K, et al. Continuous longterm immunomodulatory therapy in relapsing multiple sclerosis: results from the 15-year analysis of the US prospective open-label study of glatiramer acetate. Mult Scler 2010 16:342-50.

44. Paty DW, Li DK. Interferon beta-1b is effective in relapsingremitting multiple sclerosis. II. MRI analysis results of a multicenter, randomized, double-blind, placebo-controlled trial. UBC MS/MRI Study Group and the IFNB Multiple Sclerosis Study Group. Neurology 1993;43:662-7.

45. Goodin DS, Traboulsee A, Knappertz V, et al. Relationship between early clinical characteristics and long term disability outcomes: 16 year cohort study (follow-up) of the pivotal interferon beta-1b trial in multiple sclerosis. J Neurol Neurosurg Psychiatry 2012;83:282-7

46. Shirani A, Zhao Y, Karim ME, et al. Association between use of interferon beta and progression of disability in patients with relapsing-remitting multiple sclerosis. JAMA 2012;308:247-56.

47. O'Connor P, Filippi M, Arnason B, et al. 250 microg or 500 microg interferon beta- $1 \mathrm{~b}$ versus $20 \mathrm{mg}$ glatiramer acetate in relapsing-remitting multiple sclerosis: a prospective, randomised, multicentre study [published errata in Lancet Neurol 2011;10:115, 2009;8:981 and 2012;11:27]. Lancet Neurol 2009; 8:889-97.

48. Mikol DD, Barkhof F, Chang P, et al. Comparison of subcutaneous interferon beta-1a with glatiramer acetate in patients with relapsing multiple sclerosis (the REbif vs Glatirame Acetate in Relapsing MS Disease [REGARD] study): a multicentre, randomised, parallel, open-label trial. Lancet Neurol 2008;7:903-14

49. Trojano M, Pellegrini F, Paolicelli D, et al. Real-life impact of early interferon beta therapy in relapsing multiple sclerosis. Ann Neurol 2009;66:513-20.

50. Comi G, Martinelli V, Rodegher M, et al. Effect of glatiramer acetate on conversion to clinically definite multiple sclerosis in patients with clinically isolated syndrome (PreCISe study): a randomised, double-blind, placebo-controlled trial. Lancet 2009;374:1503-11.

51. Kinkel RP, Dontchev M, Kollman C, et al. Association between immediate initiation of intramuscular interferon beta-1a at the time of a clinically isolated syndrome and long-term outcomes: a 10-year follow-up of the Controlled High-Risk Avonex Multiple Sclerosis Prevention Study in Ongoing Neurological Surveillance. Arch Neurol 2012;69:183-90.

52. Miller DH, Chard DT, Ciccarelli O. Clinically isolated syndromes. Lancet Neurol 2012;11:157-69.

53. Polman CH, Bertolotto A, Deisenhammer F, et al. Recommendations for clinical use of data on neutralising antibodies to interferon-beta therapy in multiple sclerosis. Lancet Neurol 2010;9:740-50.

54. Killestein J, Polman CH. Determinants of interferon beta efficacy in patients with multiple sclerosis. Nat Rev Neurol 2011; 7:221-8.

55. Sormani MP, Río J, Tintore M, et al. Scoring treatment response in patients with relapsing multiple sclerosis. Mult Scler 2013 19:605-12.

56. Vennegoor A, Rispens T, Strijbis EM, et al. Clinical relevance of serum natalizumab concentration and anti-natalizumab antibodies in multiple sclerosis. Mult Scler 2013;19:593-600.

57. Río J, Tintore M, Sastre-Garriga J, et al. Change in the clinical activity of multiple sclerosis after treatment switch for suboptimal response. Eur J Neurol 2012;19:899-904.

58. European Study Group on Interferon Beta-1b in Secondary Progressive MS. Placebo-controlled multicenter randomized trial of interferon beta- $1 \mathrm{~b}$ in treatment of secondary progressive multiple sclerosis. Lancet 1998;352:1491-7.

59. La Mantia L, Vacchi L, Di Pietrantonj C, et al. Interferon beta for secondary progressive multiple sclerosis. Cochrane Database Syst Rev 2012;(1):CD005181.

60. Wolinsky JS, Narayana PA, O'Connor P, et al. Glatiramer acetate in primary progressive multiple sclerosis: results of a multinational, multicenter, double-blind, placebo-controlled trial. Ann Neurol 2007;61:14-24.

61. Hawker K, O'Connor P, Freedman MS, et al. Rituximab in patients with primary progressive multiple sclerosis: results of a randomized double-blind placebo-controlled multicenter trial. Ann Neurol 2009;66:460-71.

Affiliation: Multiple Sclerosis Center — Unit of Motor Neurorehabilitation, IRCCS Santa Maria Nascente, Fondazione Don Gnocchi, Milan, Italy

Contributors: All of the authors contributed substantially to the design and writing of the manuscript. Eleonora Tavazzi drafted the article. All of the authors critically revised the manuscript for important intellectual content, approved the final version submitted for publication and agreed to act as guarantors of the work. 